\title{
NUEVOS ESTUDIOS SOBRE LO METALINGÜÍSTICO EN ESPAÑOL
}

\author{
Ramón González Ruiz \\ Universidad de Navarra \\ Óscar Loureda Lamas \\ Universidad de La Coruña
}

\begin{abstract}
RESUMEN: En este artículo pretendemos dar noticia de una línea de investigación cuyo objeto es el análisis particularizado de las diferentes manifestaciones del metalenguaje en el español actual. Con ello, complementamos una visión parcial que ya hicimos en otro trabajo. Presentamos aquí una panorámica de los trabajos ya realizados, así como las conclusiones más generales. También se da noticia de las nuevas vías de investigación que se han abierto recientemente.
\end{abstract}

ABSTRACT: Our intention with this article is to present a series of pieces of research aiming at a specific analysis of the different aspects of the metalanguage of current Spanish. We offer an overview of what has been done, as well as some general conclusions. In addition, we briefly discuss the lines of research that have just been opened.

PALABRAS CLAVE: Metalenguaje; discurso metalingüístico; fraseología metalingüística; cultura lingüística; lengua española.

KEYWORDS: Metalanguage; metalinguistic discourse; metalinguistic phraseology; linguistic culture; Spanish.

\section{Introducción}

En otro trabajo (González Ruiz y Loureda Lamas en prensa) presentamos los primeros resultados del grupo de investigación "Lo metalingüístico en español"1. Nuestro propósito se reducía a presentar someramente las diferentes manifestaciones en el español actual de lo que podría denominarse ámbito metalingüístico del lenguaje. Se trataba, en síntesis, de demostrar la necesidad de ampliar el concepto de función metalingüística hasta abarcar una compleja, amplia y relevante serie de fenómenos: el uso de las unidades del lenguaje-objeto (o lenguaje primario) como nombres de sí mismas (p. ej., "Clima" es un sustantivo masculino); las

1. Financiado por el Programa Sectorial de Promoción General del Conocimiento del Ministerio de Cultura (ref. BFF2002-00801). Gracias a este soporte económico se ha podido realizar el presente artículo. 
palabras que en la lengua significan el hablar y sus múltiples aspectos, pertenezcan bien al léxico terminológico de la lingüística (sintagma, fonema, lexema, sinonimia, etc.), bien al léxico estructurado (en el español, charla, réplica, discurso, conversación o pregunta, en el campo léxico 'lo que se dice'; y decir, cuchichear, despotricar, mentir, charlar, etc., en el campo léxico 'hablar'); la fraseología que significa alguna dimensión del lenguaje (hablar como un carretero, no decir ni mu, predicar en el desierto, mentir como un bellaco, no tener pelos en la lengua, echar la lengua a paseo, prometer el oro y el moro, hablar por hablar, etc.); los fragmentos del discurso en estilo directo y en estilo indirecto; la lingüística misma, en tanto que lenguaje descriptivo formalizado; y, finalmente, una amplia gama de procesos pragmáticos reflexivos, algunos de los cuales están determinados idiomáticamente (por ejemplo, por medio de marcadores discursivos).

Fruto de nuestras investigaciones, que se remontan a 1998, son trabajos en los que se pretende establecer una tipología del metalenguaje, en los que se describen los comportamientos reflexivos de algunas unidades discursivas y en los que se da noticia de la visión sobre el lenguaje implícita en la lengua española, tanto en el léxico como en la fraseología.

Los campos descritos inicialmente se completan con trabajos posteriores sobre el conjunto de la fraseología metalingüística y sobre el nivel textual. Asimismo, se han abierto nuevas líneas de investigación: por ejemplo, el estudio de los refranes que fijan cualquier tipo de apreciación sobre el lenguaje o el análisis contrastivo del español con otras lenguas en el léxico metalingüístico. Por otra parte, también hemos ampliado nuestros objetivos: además de las finalidades teórica y descriptiva, principales metas en los primeros años de investigación, tratamos de encontrar la utilidad de las distinciones contenidas en las lenguas para la enseñanza, no sólo de la lengua como tal, sino también de la lingüística (en niveles iniciales).

De estos últimos avances en el terreno de lo metalingüístico queremos informar en las líneas que siguen. Organizaremos la exposición en tres partes, de acuerdo con las tres perspectivas con que se han acometido los estudios llevados a cabo en el seno del proyecto. De los dos primeras (teórica y descriptiva) ya dimos cuenta con cierto detalle en un trabajo anterior (González Ruiz y Loureda Lamas en prensa), así que solo añadiremos fundamentalmente información sobre nuevas investigaciones que se enmarcan en estas dos perspectivas. Sí nos detendremos un poco más en la tercera, dado que en la actualidad se están desarrollando algunos estudios sobre la aplicación didáctica de los significados de contenido metalingüístico (de la lengua española). 


\section{Perspectiva teórica. El dominio de lo metalingüístico}

Para delimitar el objeto de nuestras investigaciones debimos prestar atención a los términos metalingüístico metalenguaje. A nadie se le hacen extrañas estas etiquetas; pero que no sean extrañas no implica que se coincida en los fenómenos lingüísticos que pueden bautizarse como "metalingüísticos". Algunos investigadores relacionan únicamente dichos términos con la conocida función metalingüística de Jakobson y por ello reducen lo metalingüístico a usos del lenguaje para hablar del propio lenguaje. Por ejemplo: "Banco" es un término polisémico o "Examen" se escribe sin tilde $y$ con $x$.

Sin embargo, la función metalingüística, tal como la entendió Jakobson, no es sino una pequeña parcela del dominio del metalenguaje. Desde los inicios del proyecto nos dimos cuenta de que lo metalingüístico constituía un amplio y heterogéneo dominio que cobra presencia en muchos actos de habla. En el seno de nuestro proyecto se ha intentado elaborar una tipología del metalenguaje con un doble fin: deslindar el metalenguaje desde el punto de vista de la lingüística del metalenguaje visto en relación con la lógica (o, en general, visto en relación con cualquier otra propuesta de lenguaje formalizado) y establecer un marco básico en el que desarrollar las investigaciones. Esta doble finalidad se encuentra ampliamente desarrollada en algunos trabajos de Óscar Loureda Lamas, especialmente en Loureda Lamas (2001). Remitimos a este artículo para la exposición crítica de las principales concepciones teóricas sobre el metalenguaje y para la descripción de los hechos lingüísticos que cabe tildar de metalingüísticos. No obstante, apuntamos a continuación muy brevemente algunas propuestas con el fin de situar los trabajos descriptivos del siguiente apartado.

En términos generales, la tipología del metalenguaje en que se han apoyado nuestras investigaciones descansa en la distinción entre el discurso metalingüístico y el metalenguaje de la lengua. El discurso metalingüístico tiene que ver con un decir del lenguaje. Por tanto, forman parte del discurso metalingüístico aquellos enunciados en los que se dice algo del lenguaje o de cualquiera de sus aspectos: por ejemplo, El chino no es tan difícil como parece. Los comentarios que emiten los hablantes sobre cualquier aspecto de lo lingüístico no pertenecen al lenguaje ni a las lenguas como tales: si alguien dice Las lenguas con pocas palabras son lenguas inútiles es él el responsable de la afirmación, no la lengua en la que se expresa (en este caso, el español). Ahora bien, algunos lingüistas, como Johannes Kabatek (2000), han advertido de que estos juicios no son del todo intranscendentes. Muy a menudo, el hablante se convierte en "lingüista" y persigue valorar algún hecho lingüístico; intenta, en definitiva, hablar de su lenguaje o del de los demás, valorándolo casi siempre. Y estos comentarios pueden influir indirectamente 
en el comportamiento lingüístico y modificar en última instancia la lengua, pues se crean actitudes que deben ser estudiadas por los sociolingüistas.

En segundo lugar, hay un metalenguaje que es fruto del hacer con el lenguaje. En él se incluyen todos los fenómenos reflexivos que muestran el lenguaje, las lenguas y los textos. Son fenómenos que pertenecen, pues, al lenguaje, las lenguas y los textos como tales. En primer lugar, aquí cabe el uso metalingüístico del lenguaje primario: se trata de usos que se encuadran en la conocida función metalingüística de Jakobson, como los ejemplificados más arriba ("Banco" es una palabra polisémica), usos que responden a ciertas reglas gramaticales específicas, diferentes a las del uso no metalingüístico (cf. Gutiérrez Ordóñez 1997 y Castillo Peña 1998 y en prensa). En segundo lugar, incluimos aquí todos los significados de las lenguas que se refieren a algún aspecto del lenguaje. El lenguaje mismo, en efecto, como parte de la realidad que es, se halla segmentado por los significados de los idiomas. En particular, esto se comprueba en una notable parcela del léxico y en una generosa nómina de unidades fraseológicas. En el seno del proyecto hemos dedicado los principales esfuerzos a describir este dominio idiomático de significado metalingüístico en la lengua española, si bien ya se han empezado a hacer calas en otras lenguas románicas.

\section{Perspectiva descriptiva}

\subsection{Descripción y análisis de las motivaciones del uso metalingüístico}

En nuestras investigaciones queremos dar cuenta de los empleos y motivaciones del uso metalingüístico en el hablar corriente. Muchas veces empleamos los signos relacionándolos conscientemente con otros signos (de la propia lengua o de otra) o con otros textos o fragmentos de textos conocidos. En los chistes este recurso metalingüístico sirve para generar desenlaces cómicos: por ejemplo, ¿Cómo se llama el director de una clínica japonesa? Dr. Sekuro Ketekura. ¿Y el jefe de urgencias de esa misma clínica? Dr. Takurado Yamimo. En estos casos, en la configuración de los signos se imita la forma sonora de los significantes del japonés (o, mejor, lo que culturalmente se interpreta como la forma sonora del japonés). Análogos procesos se desencadenan en casos de deformación de palabras: burrocracia, por burocracia, sociolisto, por socialista, o autonosuyas, por autonomías; en la modificación de frases hechas, en la publicidad, como en No compre sin Thom ni Son (por sin ton ni son), o en chistes, como en Este era un padre que tenía un hijo que se llamaba Albino. Un día, cansado de que Albino siempre llegara tarde a comer, salió a buscarlo con una escopeta. Cuando lo encontró disparó al aire dos tiros. Y al pam pam, Albino vino (relación 
consciente con la expresión decir al pan, pan, y al vino, vino); también en traducciones "al pie de la letra", como en Las aves del César murieron por falta de salud (traducción chistosa de Ave Cesar morituri te salutant). Se trata, en todos los casos, de estudiar estos procedimientos que asocian en el hablar (en el nivel del texto) la información extralingüística (el conocimiento de las cosas) a la información lingüística (significados y significantes) para servir a otros fines (publicitarios o humorísticos, por ejemplo).

\subsection{Descripción de los significados de contenido metalingüístico}

Como se ha apuntado más arriba, la mayor parte de los trabajos inscritos en el proyecto de investigación han dirigido su mirada a describir las diversas parcelas del español con significado metalingüístico. En el cuadro que se presenta a continuación se especifican, ilustradas con algunos ejemplos, las diversas esferas idiomáticas en que se pueden presentar estos contenidos metalingüísticos (cf. González Ruiz 2004):

\section{LO METALINGÜÍSTICO EN LA LENGUA ESPAÑOLA}

\begin{tabular}{|c|c|c|}
\hline \multirow{2}{*}{\begin{tabular}{|c|} 
LÉXICO \\
METALINGÜÍSTICO
\end{tabular}} & \multirow{2}{*}{\multicolumn{2}{|c|}{\begin{tabular}{|l} 
Léxico terminológico: frase, sintagma, homonimia, fonema, sema \\
Léxico común: explicación, aviso, murmurar, telegrama, conversación
\end{tabular}}} \\
\hline & & \\
\hline \multirow{6}{*}{$\begin{array}{c}\text { FRASEOLOGÍA } \\
\text { METALINGÜÍSTICA }\end{array}$} & \multicolumn{2}{|c|}{$\begin{array}{l}\text { Colocaciones y locuciones (sin significado gramatical): contestar con } \\
\text { evasivas; decir de todo corazón; decir a boca llena; hablar como un } \\
\text { papagayo; discutir acaloradamente }\end{array}$} \\
\hline & \multirow{2}{*}{$\begin{array}{l}\text { Locuciones } \\
\quad(\text { con } \\
\text { significado } \\
\text { gramatical) }\end{array}$} & $\begin{array}{l}\text { Locuciones marcadoras: ya te digo; mejor dicho; o como } \\
\text { se llame; dicho sea entre paréntesis; hablando mal y pronto }\end{array}$ \\
\hline & & Locuciones modalizadoras: la verdad sea dicha; a decir verdad \\
\hline & \multirow{3}{*}{$\begin{array}{l}\text { Enunciados } \\
\text { fraseoló- } \\
\text { gicos }\end{array}$} & $\begin{array}{l}\text { Refranes: Quien dice lo que siente, ni peca ni miente; } \\
\text { Desconfía del que miente, detrás hay un delincuente }\end{array}$ \\
\hline & & $\begin{array}{l}\text { Enunciados de valor específico: Hablando del rey de } \\
\text { Roma, por la puerta asoma; Habló el buey y dijo mu; Así se } \\
\text { cuenta la Historia; (Eso) son ganas de hablar; Habló/Lo } \\
\text { dijo Blas, punto redondo }\end{array}$ \\
\hline & & $\begin{array}{l}\text { Fórmulas rutinarias: ¡no me digas!; ¿a mí qué me cuentas?; } \\
\text { Me (lo) ha dicho/contado un pajarito; No hay más que hablar }\end{array}$ \\
\hline
\end{tabular}


Los ejemplos que se acaban de proponer dan cuenta de que en diversos sectores idiomáticos (en el léxico y en la fraseología) está depositada una cultura lingüística. A nosotros nos interesa la cultura lingüística como concepción sobre el lenguaje y el hablar que muestran las lenguas en sus distinciones: se trata, en una palabra, de analizar el modo en que las lenguas comprenden, como parte de la realidad, el lenguaje. A continuación recogemos, de manera panorámica, los avances realizados en el marco del proyecto que han tenido como objeto la descripción de la cultura lingüística de la lengua española (de España).

\subsubsection{La cultura lingüística implícita en la lengua español (I): el léxico}

En el seno del proyecto se han realizado varios trabajos que tienen como objeto el léxico (común, no terminológico) que identifica alguna dimensión del lenguaje. Así, se han estudiado principalmente las voces que nombran tipos de texto: charla, conferencia, monólogo, informe, anuncio, aviso, etc. (cf. Loureda Lamas 2003). También se han descrito monográficamente (cf. Loureda Lamas 1999) los adjetivos que se pueden aplicar a las personas en tanto que hablantes (locuaz, dicharachero, badulaque, bienhablado, mordaz, etc.) o a los discursos como tales (por ejemplo, lapidario, obvio, conciso, escueto, sucinto, redundante o macarrónico). A diferencia de los lexemas que nombran los tipos de texto, los adjetivos con que habitualmente se valora a los hablantes y a sus discursos no son voces que significan cualidades exclusivas de aquellos (así, al lado de un discurso denso/extenso/aburrido/ inteligente, tenemos un líquido denso, un terreno extenso, una película aburrida, una actuación inteligente, etc.). Actualmente también se están realizando, en los ámbitos léxicos reseñados, estudios que comparan el léxico metalingüístico del español y del gallego.

Otro campo del léxico metalingüístico al que nos hemos acercado lo conforman los nombres de las funciones del hablar en una situación determinada, esto es, los nombres de los sentidos de los actos de habla. En rigor, se trata de dos tipos de catálogos que remiten a dos clases de funciones que se pueden dar en los discursos: las funciones textuales, es decir, aquellas que se dan en los textos como contenido propio $^{2}$, y las funciones idiomáticas, es decir, aquellas que se dan en los textos

2. La función textual, que podemos denominar también sentido, designa el contenido propio de un texto o de una parte de un texto. Así, por ejemplo, "pregunta", "respuesta", "orden", "asentimiento", "conclusión", "resumen", etc. son, entre otras muchas, funciones textuales o sentidos. 
como nivel estructurado de un idioma ${ }^{3}$. El catálogo de funciones de los discursos no coincide con el de los nombres de los tipos de texto. Como se ha mostrado en Loureda Lamas (en prensa a), son tres las combinaciones posibles. En primer lugar, pueden coincidir los nombres de los tipos de texto con los nombres de las funciones textuales (y si hay estructuras de específicas de la lengua, de las funciones idiomáticas):

\begin{tabular}{|r|l|}
\hline \multicolumn{2}{|c|}{ NOMBRES DE TIPOS DE TEXTO } \\
Y NOMBRES DE FUNCIONES TEXTUALES & UNIDADES FUNCIONES TEXTUALES ANTERIORES \\
\hline aclaración & mejor dicho... \\
\hline advertencia & ojo, cuidado, oye, mira... \\
\hline afirmación & exacto, cierto, desde luego, por descontado... \\
\hline digresión & por cierto, a propósito, dicho sea de paso, a todo esto... \\
\hline enumeración & primero, segundo...; en primer lugar, en segundo lugar... \\
\hline explicación & es decir, o sea, en otras palabras... \\
\hline matización & mejor dicho, bueno... \\
\hline recapitulación & en suma, en resumidas cuentas, en fin... \\
\hline refutación & pues, en absoluto, de ninguna manera... \\
\hline réplica & pues \\
\hline resumen & en resumen, total, en una palabra... \\
\hline
\end{tabular}

En segundo lugar, es posible que algunos términos que nombran tipos de discurso no puedan identificar clases de funciones textuales (o, en su caso, funciones idiomáticas). Dan testimonio de este conjunto las siguientes lexías: antetítulo, falacia, fe de erratas, historia, lema, libelo, maledicencia, manual, manuscrito, preámbulo, subtítulo, texto o título; también aforismo, anécdota, apotegma, autobiografía, biografía, borrador, carta, chiste, chuleta, coletilla, créditos, cuento, cuestionario, currículum, dictado, epitafio, eslogan, exordio, fábula, guión, historial, índice, indirecta, letra, leyenda, máxima, memorias, nómina, parábola, perogrullada, posdata, prólogo, proverbio, pulla, receta, refrán, trabalenguas o vademécum.

Finalmente, algunos nombres de funciones textuales (e idiomáticas) no pueden significar tipos de texto. Son, por ejemplo, apertura de discurso, aprobación, asentimiento, atenuación, causalidad, concesión, conclusión, condición, consecuencia, continuación, contraste, corrección, culminación, deducción, duda, equivalencia, evidencia, inferencia, intensificación, llamada de atención, mantenimiento de la atención del interlocutor, oposición, reformulación, refuerzo (o énfasis), restricción, topicalización (tematización) o transición.

3. La función idiomática, o significado de un texto en sentido estricto, designa el contenido del nivel discursivo proporcionado por las unidades idiomáticas de una lengua histórica determinada. 


\subsubsection{La cultura lingüística implícita en la lengua español (II): la fraseología}

Como se ha podido apreciar en el cuadro síntesis presentado en el epígrafe anterior, los contenidos metalingüísticos tienen presencia en los tipos de unidades fraseológicas que han sido distinguidos en los estudios de fraseología ${ }^{4}$. En el sector de las colocaciones y locuciones, existe un conjunto de expresiones que contienen un verbo de lengua (hablar/decir entre dientes, hablar/decir pestes de alguien, hablar/decir en cristiano, preguntar a bocajarro, no decir/pronunciar una palabra más alta que otra, decir/contar de pe a pa, mentir como un bellaco, contestar con evasivas, hablar con lengua de trapo, hablar por hablar, hablar gangoso, decir de todo corazón, hablar sin ton ni son, etc.) $)^{5}$. Se trata del grupo más numeroso y del que, hasta donde tenemos noticia, existen algunas descripciones minuciosas para la lengua española, la mayor parte de ellas elaboradas en el marco de nuestro proyecto de investigación. Se han estudiado principalmente aquellas que contienen los verbos decir y hablar, que representan las dos unidades archilexemáticas del campo semántico de los verbos de lengua (cf. Fernández Bernárdez 2002 y Aznárez Mauleón 2000 y 2004) y que, por ello, permiten con más facilidad especificar su contenido semántico con complementos (argumentales o no). Por otro lado, se encuentran expresiones cuyo contenido alude a la realidad del lenguaje pese a que carecen en su composición de verbos de lengua. En este segundo grupo el término relacionado con el lenguaje está

4. En las clasificaciones que se han realizado en los estudios fraseológicos se pueden distinguir dos concepciones: una "ancha" y otra "estrecha". La primera incluye entre las expresiones fraseológicas tanto las unidades equivalentes a palabras o sintagmas como a las unidades equivalentes a oraciones o textos. La segunda reduce el ámbito de la fraseología a las expresiones que equivalen a la palabra o al sintagma. No entraremos aquí en esta polémica ni en justificar nuestra posición. Únicamente diremos que, a efectos de claridad expositiva, se han incluido en el ámbito fraseológico enunciados fraseológicos como los refranes y las fórmulas o expresiones rutinarias cuyo significado es de carácter reflexivo o metalingüístico.

5. La distinción entre locuciones y colocaciones se apoya en las dos propiedades fundamentales de las unidades fraseológicas: la fijación y la idiomaticidad. Según Ruiz Gurillo (1998, 12), la fijación es una propiedad necesaria que "puede comprenderse como complejidad o estabilidad de forma y, adicionalmente, como defectividad combinatoria y sintáctica"; y la idiomaticidad es una propiedad subsidiaria, "según la cual el significado de la estructura no puede deducirse del significado de sus partes, tomadas por separado o en conjunto". Las colocaciones presentan un menor grado de fijación que las locuciones y generalmente nula idiomaticidad, por lo que se encuentran en la periferia del continuum fraseológico, de ahí que algunas de ellas estén cercanas al límite que separa las unidades fraseológicas de las combinaciones libres. Se trata de combinaciones que "debido a su fijación en la norma, presentan restricciones de combinación establecidas por el uso, generalmente de base semántica" (Corpas Pastor 1996, 66). Aunque su grado de fijación es diverso, todas las expresiones metalingüísticas que presentan un verbo de lengua son semiidiomáticas, dado que el contenido del verbo de lengua se mantiene en su sentido literal, de ahí que se sitúen en el ámbito de las colocaciones. 
representado o por alguna parte del cuerpo humano vinculada con la actividad verbal o por otras voces metalingüísticas como el sustantivo palabra o lexemas que se refieren al código gráfico (comerse las palabras, poner los puntos sobre las íes, morderse la lengua, no abrir la boca, no tener pelos en la lengua, darle a la sinhueso, etc.). Algunas, en fin, contienen tanto un verbo de lengua como otro lexema metalingüístico: contar con puntos y comas, no decir/no hablar palabra, decir al pie de la letra, etc.

Las conclusiones generales de los estudios que han tenido como objeto la expresiones fraseológicas con un verbo de lengua han insistido en los mismos aspectos: e insiste, por ejemplo en que la mayor parte de los fraseologismos remiten a la actividad individual del hablar, a sus productos (los textos) y a la compleja gama de normas que "rigen" la adecuación de las palabras a los elementos de la situación comunicativa (hablante, oyente, la relación entre ambos, canal, contexto). En este sentido, como se apuntará más adelante, la lingüística implícita en la fraseología metalingüístico es de corte pragmático.

Un punto de vista con el que, recientemente, se ha comenzado a abordar el mundo de los fraseologismos metalingüísticos atañe al análisis de los procesos metafóricos productivos en la creación de unidades fraseológicas con significado metalingüístico. En este sentido se están estudiando las metáforas conceptuales, es decir, los esquemas abstractos que sirven para agrupar las expresiones metafóricas en que se basan los significados metafóricos de índole metalingüística (cf. Lakoff \& Johnson 1986). Así, se han podido establecer las metáforas conceptuales productivas agrupando las unidades fraseológicas según los dominios origen que se proyectan en el dominio destino LENGUAJE. He aquí un elenco de ejemplos de metáforas metalingüísticas organizadas de acuerdo con las metáforas conceptuales que generan correspondencias entre dominios:

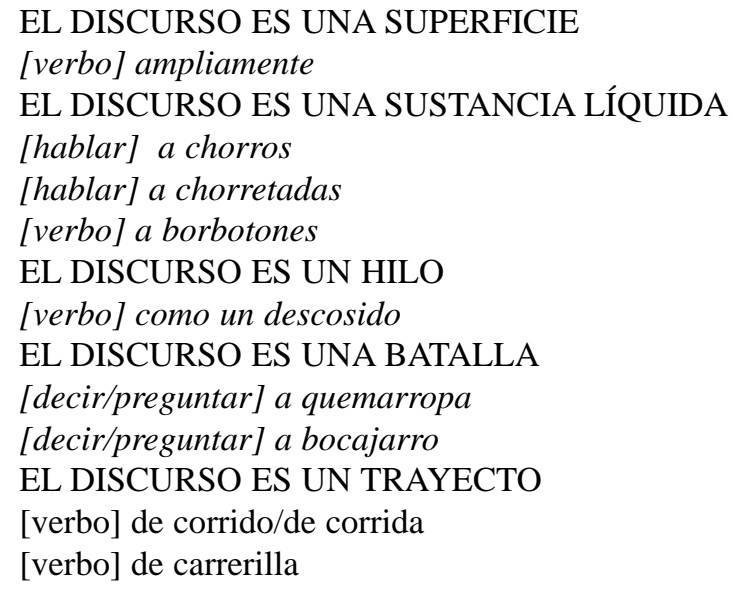


En la actualidad, varios miembros del equipo investigador están trabajando en las metáforas metalingüísticas con un amplio corpus de expresiones fraseológicas. Su organización y análisis serán, según creemos, un interesante aporte para perfilar cómo el ser humano percibe, ordena y categoriza esa parte del mundo que es el lenguaje.

\subsubsection{La cultura lingüística implícita en la lengua español (III): los refranes}

Otro ámbito relevante para el estudio de la cultura lingüística implícita en la lengua española es el de ciertos juicios sobre el lenguaje, y las actitudes implícitas en ellos, que han trascendido el plano de lo individual. Forman parte de la memoria textual colectiva de una comunidad dada, memoria en la que caben, por ejemplo, los refranes, los proverbios y los dichos. Estos textos recogen valores y normas sobre el hablar y el lenguaje que sólo son atribuibles a una comunidad lingüística como tal: quien emplea un refrán, por ejemplo, es responsable de su inclusión en su acto de habla, pero no lo es en última instancia de su constitución como refrán ni de la visión del mundo que en él se encierra. Los refranes metalingüísticos constituyen un valioso testimonio de aquello que la propia comunidad de habla española considera como el "deber ser" del lenguaje. En la actualidad el análisis y clasificación de la "lingüística implícita" reflejada en nuestro refranero está siendo objeto de una tesis doctoral. Algunas conclusiones parciales de este trabajo pueden verse en Manero Richard (2000 y 2001).

Como se va a comprobar a continuación, aquí no se agota el dominio idiomático de contenido metalingüístico. Sin embargo, es el ámbito del léxico, de la fraseología de contenido no gramatical y de los refranes donde especialmente queda objetivada lo que entendemos aquí como cultura lingüística. El análisis de los significados de estos sectores idiomáticos responde a uno de los objetivos principales de nuestro proyecto de investigación: tener una visión completa de cómo concibe el lenguaje la comunidad de habla española.

\subsubsection{Descripción de los significados de contenido metalingüístico (IV). Los significados gramaticales de contenido metalingüístico}

Algunas investigaciones del proyecto se han centrado en describir las propiedades formales, semánticas y pragmáticas de unidades fraseológicas de contenido metalingüístico que funcionan como locuciones marcadoras, como fórmulas cuyo significado se vincula al 'hablar con sinceridad': la verdad sea dicha, a decir verdad (ver González Ruiz 2000 y González Ruiz y Aznárez Mauleón en prensa a, 
en prensa b y en prensa c). En el seno del proyecto se han descrito fraseologismos metalingüísticos, principalmente locuciones marcadoras y fórmulas, orientados a desempeñar alguna función metadiscursiva como la digresión, la reformulación, la enumeración, la atenuación o la intensificación (cf. Loureda Lamas 2000 y 2002, Pérez-Salazar en prensa a y en prensa b, Aznárez Mauleón 2004, Aznárez Mauleón y González Ruiz en prensa a, en prensa b y en prensa c). Se trata, en estos casos, no ya de expresiones con un contenido primariamente descriptivo, sino de unidades que desempeñan, en el nivel del texto, alguna función pragmática o textual o que sirven para expresar relaciones sociales o actitudes ante el discurso (propio o ajeno). Por lo tanto, son expresiones en que priman más las funciones interactiva y textual que la descriptiva, dado que su uso se orienta a regular las relaciones interpersonales mediante funciones discursivas como la aprobación o aceptación, la intensificación y la atenuación; a manifestar contenidos emocionales ante lo dicho o lo por decir; y a organizar el discurso aportando instrucciones reflexivas relacionadas con su formulación (véanse algunos ejemplos en el cuadro presentado al inicio del apartado 2).

\section{Perspectiva aplicada. La cultura lingüística y la enseñanza de la lengua}

Algunos de los últimos trabajos realizados en el seno del proyecto "Lo metalingüístico en español" han perseguido ilustrar la aplicabilidad, en diferentes ámbitos docentes, de la cultura lingüística objetivada en los significados metalingüísticos (cf. González Ruiz y Loureda Lamas 2003 y González Ruiz 2003 y 2004). Dicho de otra manera: en estos trabajos se ha intentado responder a la pregunta de si la gran cantidad de intuición y experiencia almacenada en los significados de contenido metalingüístico puede tener alguna utilidad para la enseñanza de la lengua y de la lingüística como tal. Para responder a esta pregunta cabría dejar asentado, para no cometer equivocaciones en la perspectiva aplicada que aquí queremos esbozar, qué tipo de conocimiento es el que manifiestan los significados lingüísticos (metalingüísticos o no). En términos aristotélicos, el lenguaje es esencialmente logos semántico, expresión con significado. Se suele decir que el lenguaje es el instrumento con el que primariamente el ser humano "accede" al mundo. Pues bien, este "acceso" se lleva a cabo por el "puente" de los significados lingüísticos que no son sino las objetivaciones que damos a las captaciones intuitivas de la realidad. En términos de Eugenio Coseriu, "la estructuración lingüística es ya conocimiento, pero, precisamente, sólo la primera etapa del conocimiento, un conocimiento sólo diferenciador, en el que se aprehende simplemente como en sí mismo idéntico (uniforme) y como diferente de lo demás" (Coseriu 1991, 45). De aquí se deduce que la lingüística implícita en los significados 
idiomáticos de contenido metalingüístico es intuitiva, es decir, las distinciones que, pongamos por caso, vienen dadas en los significados del léxico y de la fraseología metalingüísticos del español no son fruto de un ejercicio científico, reflexivo. No hay que confundir, pues, cultura, en este caso cultura lingüística, con las distinciones que nos proporciona la ciencia (en este caso la Lingüística como ciencia del lenguaje).

Todo esto no quiere decir, naturalmente, que las intuiciones objetivadas en los significados metalingüísticos sean irrelevantes. Son relevantes, en primer lugar, porque precisamente muestran lo que es relevante (e intrascendente) en una comunidad lingüística concreta. Pero, además, según hemos tenido ocasión de comprobar tras las calas descriptivas hechas en distintas esferas idiomáticas de contenido metalingüístico, la lingüística implícita que se deduce de sus distinciones semánticas es de sumo interés para el lingüista y para el docente. Para el primero -para el lingüista- el interés del saber acumulado en los significados metalingüísticos se comprende si se acepta que el lingüista debe estar atento a la realidad de los hablantes. Coseriu ha señalado que "La lingüística dice lo que los hablantes ya saben, pero lo dice en un grado más elevado de conocimiento" (1992, 252) ${ }^{6}$. En este sentido, el lingüista (y el docente) no debería desviar la mirada ante el caudal de conocimientos mancomunados sobre el lenguaje que están depositados en las lenguas mismas. De hecho, el propio Coseriu fue coherente con este principio metodológico. Su conocida tríada de los tres tipos de conocimientos o saberes lingüísticos (saber elocutivo o saber hablar en general, saber idiomático o saber hablar un idioma y saber expresivo o saber construir textos en situaciones determinadas, en momentos prácticos concretos) que se corresponden con tres niveles o escalones del hablar (universal, histórico e individual) tienen su base en el saber intuitivo de los hablantes. Es decir, un individuo, en cuanto hablante, es capaz de deslindar intuitivamente tres niveles en el lenguaje que conjuntamente representan el saber hablar como conocimiento técnico del lenguaje. No sorprende, en este sentido, que, según se ha comprobado en nuestras investigaciones, la organización primaria de los significados codificados en los fraseologismos responde a las distinciones terminológicas, de raigambre clásica, sistematizadas por Coseriu.

6. Y dice más adelante: "La distinción entre el saber técnico de los hablantes y el saber reflexivo de los lingüistas proporciona a la lingüística descriptiva, que en nuestra época muchos equiparan en gran parte con la lingüística sin más, su total legitimidad, puesto que su cometido consiste en reflejar el saber de los hablantes 'naïf' y formularlo en un grado más alto de conocimiento" (Coseriu 1992, 254). 
Esto quiere decir que los significados metalingüísticos pueden ser una herramienta interesante para la enseñanza de la competencia lingüística en tanto que conjunto de saberes que los hablantes pueden poner en marcha en su actividad verbal. Los trabajos que han tenido como objeto distintas parcelas de la fraseología metalingüística ilustran bien lo que se acaba de esbozar ( $c f$. especialmente González Ruiz 2004, Aznárez Mauleón 2000 y 2004 y Fernández Bernárdez 2002).

No se agota aquí la rentabilidad didáctica de la cultura lingüística. No disponemos aquí del espacio suficiente para explicar en detalle esta perspectiva aplicada. Enumeraremos, no obstante, algunos datos que pueden ser ilustrativos de la proyección aplicada de los significados metalingüísticos.

Un hecho sobre el que han llamado la atención la mayor parte de los estudios realizados en el marco de nuestro proyecto atañe a la constatación del amplio número de expresiones que codifican infracciones, insuficiencias o, en definitiva, valoraciones negativas con respecto a las competencias que se integran en los planos biológico y cultural del lenguaje. No es difícil dar algunas muestras. Entre las expresiones que valoran la intensidad o el volumen del discurso hay un buen número que codifica la intensidad como 'excesivamente alta' o 'excesivamente baja'. Por ejemplo: hablar/decir algo a grito pelado/limpio/herido, hablar/decir algo a gritos, hablar/decir algo a voces, hablar/decir algo a voz en cuello, etc. Con verbos de lengua que no son ni hablar ni decir, los significados se refieren generalmente a comportamientos que se valoran negativamente; por ejemplo, con predicar en (el) desierto se codifica la ausencia de efectos perlocutivos y con contestar con evasivas y con preguntar a bocajarro quedan sancionados actitudes o comportamientos inapropiados o no cooperativos. Un buen número de unidades fraseológicas se refiere a la incongruencia, a la irreflexión o al desconocimiento previos al discurso: [verbo] a tontas y a locas, [verbo] a vuela pluma, [verbo] sin fundamento, [verbo] sin ton ni son, [verbo] al (buen) tuntún, etc.; otras muchas se refieren a la inadecuación o inoportunidad del discurso con respecto a los factores del hablar, como en hablando mal y pronto o en hablar de la soga en casa del ahorcado; o, por fin, otros fraseologismos se refieren a comportamientos descorteses que pueden ofender al destinatario, como sucede con mentar la madre a alguien. A pesar de lo que exiguo de la muestra, creemos que con estos ejemplos queda ilustrada la importancia cuantitativa de los significados que se refieren a lo que no se espera, a la violación de expectativas, es decir, a lo que podríamos denominar comportamientos marcados. En este sentido, las expresiones de significado metalingüístico no son diferentes de otros fraseologismos, dado que, según Wotjak (1998, 542), las expresiones fraseológicas suelen expresar preferentemente valoraciones negativas o peyorativas respecto de comportamientos, conductas, cualidades morales, etc. Quizá huelga apuntar el interés didáctico de estas expresiones: en ellas los alumnos tienen reunida una rica y matizada tipología de deficiencias expresivas. 
En otro orden de cosas, la utilidad atañe a la distribución numérica de unidades fraseológicas que se sitúan en el plano cultural del lenguaje. Son mucho más numerosas las expresiones que específicamente codifican contenidos atingentes al saber expresivo o discursivo, es decir, a saber construir productos verbales de acuerdo con los factores del hablar. Esto es un indicio, entre otras cosas, de que el criterio, en términos de Coseriu, de la propiedad es más complejo que el de la congruencia y el de la corrección idiomática. La dimensión pragmática de lo apropiado corresponde a los diversos elementos que intervienen en la interacción: el hablante con sus intenciones, el tema, los oyentes, el momento práctico en que se habla, además de otros como el canal de transmisión. Por otra parte, también está representada en los significados metalingüísticos otra dimensión pragmática: aquella que se refiere a la intención o finalidad de las palabras. Así, en el significado de hablar de chanza, hablar de mentirijillas o en hablar con retintín se alude a la intención de hablar con tono bromista o irónico; o en hablar con segundas, por ejemplo. Otras codifican que la intención del hablante no se corresponde con lo que se ha expresado: así, en decir de boquilla. En González Ruiz (2004) se encuentran abundantemente ejemplificadas estas dos dimensiones pragmáticas con fraseologismos metalingüísticos. También se ha comprobado la índole pragmática en las calas del léxico metalingüístico (cf. Loureda Lamas 2003, en prensa a y en prensa b). Se ha advertido q el la sustancia semántica del campo léxico 'lo que se dice' las oposiciones se efectúan con base en rasgos de carácter pragmático; dicho de otro modo, las distinciones entre los lexemas implican que los textos se presentan, en la experiencia de los hablantes del español, como actos de habla y como su producto. Se entiende que en los discursos hay más que palabras: existe un hablante, un oyente, un contexto o circunstancias, una finalidad, un medio de comunicación y un discurso como tal, con un contenido, a veces con un tema, y con una serie heterogénea de aspectos formales.

Con estos breves apuntes pensamos que ha quedado ilustrada la idea de que los conocimientos que sobre el lenguaje están depositados en los idiomas constituyen un interesante filón para la enseñanza de la lengua y de la Lingüística (también de la Pragmática como tal).

\section{Final}

En las páginas precedentes hemos pretendido ofrecer una visión sintética de los trabajos acometidos en el seno del grupo investigador "Lo metalingüístico en español" y de otros que están en vías de realización. Con este esbozo panorámico, complementario del que expusimos en González Ruiz y Loureda Lamas (en prensa), 
se ha podido percibir que lo metalingüístico cobra presencia en muchas ocasiones. Por ello, desde el principio de nuestros estudios consideramos necesario establecer, desde el punto de vista teórico, una tipología del metalenguaje que sirviera para organizar las futuras investigaciones. Hasta ahora, la mayor parte de los trabajos se ha orientado a describir los significados metalingüísticos de la lengua española. La rica cantidad de datos reunidos en estos trabajos y las conclusiones a que en ellos se ha llegado nos ha ayudado a obtener una visión global de la lingüística implícita en la lengua española. Ello nos ha convencido de la relevancia de la intuición almacenada en el amplio espacio idiomático de significado metalingüístico. Y también nos ha animado a reflexionar sobre sus posibles aplicaciones docentes.

Recientemente se han iniciado estudios sobre otras lenguas románicas. Provisionalmente, se puede decir que la cultura lingüística que objetivan estas lenguas no difiere de la de la lengua española: es una lingüística esencialmente pragmática. Permítasenos por ello concluir con las mismas palabras con las que finalizábamos el estudio mencionado:

[...] los hablantes del español (también los de otras lenguas occidentales) tienen, o tenemos, una concepción pragmática del hablar mucho antes de que los lingüistas se fijaran en el texto o discurso como realidad última del lenguaje. Por lo tanto, si los lingüistas no fueron "pragmáticos" con anterioridad en parte se debe a que no repararon lo suficiente en las distinciones que las lenguas les indicaban desde chicos.

\section{Bibliografía}

AZNÁREZ MAULEÓN, Mónica. "Comunicación no verbal y discurso en la fraseología metalingüística con los verbos hablar y decir en español actual". RILCE, 2000a, 16 (2), p. 213-224.

- Estudio fraseológico de las expresiones metalingüísticas con el verbo hablar en español actual. Tesis de Licenciatura inédita. Pamplona: Universidad de Navarra, 2000b.

— "La enseñanza de la fraseología en el aula de E/LE: el caso de las expresiones metalingüísticas con el verbo hablar". En: FRANCO, M. et al. (eds.). Nuevas perspectivas en la enseñanza de español como lengua extranjera. Actas del $X$ Congreso Internacional de ASELE. Vol. I. Cádiz: Universidad de Cádiz, 2001, p. 87-96.

- La fraseología metalingüística con verbos de lengua en española actual. Tesis Doctoral inédita. Pamplona: Universidad de Navarra, 2004. 
AZNÁREZ MAULEÓN, Mónica. "El metalenguaje en la norma: colocaciones metalingüísticas del tipo verbo + adv. en -mente". En: CASADO VELARDE, Manuel; Ramón GONZÁLEZ RUIZ y Óscar LOUREDA LAMAS (eds.). Estudios sobre lo metalingüístico en español. Frankfurt am Main: Peter Lang GmbH, Europaeischer Verlag der Wissenschaften. En prensa.

- y Ramón GONZÁLEZ RUIZ. "Semántica y pragmática de algunas expresiones de sinceridad en el español actual". En: CASADO VELARDE, Manuel; Ramón GONZÁLEZ RUIZ y M ${ }^{\mathrm{a}}$ Victoria ROMERO GUALDA (eds.). Actas del Congreso Internacional "Análisis del discurso: lengua, cultura, valores". Madrid: Arco/Libros. En prensa a.

— "Aproximación desde el NSM a la semántica y pragmática de algunas expresiones de sinceridad en español actual". En: CASADO VELARDE, Manuel; Ramón GONZÁLEZ RUIZ y Óscar LOUREDA LAMAS (eds.). Estudios sobre lo metalingüístico en español. Frankfurt am Main: Peter Lang $\mathrm{GmbH}$, Europaeischer Verlag der Wissenschaften. En prensa b.

- "Francamente, el rojo te sienta fatal. An approach to the semantics and pragmatics of some expressions of sincerity in present-day Spanish". En: PEETERS, Bert (ed.). Semantic Primes and Universal Grammar. Empirical findings from the Romance Languages. Amsterdam-Philadelphia: John Benjamins. En prensa c.

— et al. "Tres calas (más) en el metalenguaje del español". Anuario de Estudios Filológicos, 2002, 16, p. 17-33.

CASADO VELARDE, Manuel. "Semántica y Pragmática en el léxico metalingüístico (metadiscursivo) del español actual". En: GUTIÉRREZ-REXACH, Juan (ed.). Meaning and the Components of Grammar/El significado y los componentes de la gramática. Múnich: LINCOM Europa, 2001, p. 173-192.

CASTILLO PEÑA, Carmen. "Función metalingüística, metalenguaje y autonimia". Lexis, 1998, 22 (2), p. 243-266.

- "La gramática de las unidades autónimas del español". En: CASADO VELARDE, Manuel; Ramón GONZÁLEZ RUIZ y Óscar LOUREDA LAMAS (eds.). Estudios sobre lo metalingüístico en español. Frankfurt am Main: Peter Lang GmbH, Europaeischer Verlag der Wissenschaften. En prensa.

CORPAS PASTOR, Gloria. Manual de fraseología española. Madrid: Gredos, 1996.

COSERIU, Eugenio. El hombre y su lenguaje. 2a ed. Madrid: Gredos, 1991.

- La competencia lingüística. Elementos de una teoría del hablar. Madrid: Gredos, 1992.

FERNÁNDEZ BERNÁRDEZ, Cristina. Expresiones metalingüísticas con decir. La Coruña: Universidad, 2002. 
GONZÁLEZ RUIZ, Ramón. "Felicidades, sinceramente, don Antonio. A propósito de los adverbios de enunciación". RILCE, 2000, 16 (2), 289-324.

— "Alcances y límites de la cultura lingüística implícita en la lengua española". En: XXXIII Simposio de la Sociedad Española de Lingüística. Gerona, 16-19 de diciembre de 2003.

— "¿Qué sabe la fraseología del lenguaje?: fraseología de contenido metalingüístico y enseñanza de la lengua". En: GONZÁLEZ CALVO, José Manuel; José TERRÓN GONZÁLEZ y Juan Carlos MARTÍN CAMACHO (eds.). Actas de las VII Jornadas de Metodología y Didáctica de la Lengua Española: las Unidades Fraseológicas. Cáceres: Universidad de Extremadura, 2004, p. 153-184.

— "Atenuación, intensificación y modalizadores de sinceridad". En: Actas del VI Congreso de Lingüística General. Santiago de Compostela. En prensa.

- y Óscar LOUREDA LAMAS. "Cómo aprovechar las distinciones intuitivas de la lengua (española) para la enseñanza de la Lingüística". En: IV Congreso de Investigaciones Lingüístico-Filológicas. Lima: Universidad Ricardo Palma, 4-9 de agosto de 2003.

— "Algunos estudios recientes sobre lo metalingüístico en español". Verba. En prensa.

GUTIÉRREZ ORDÓÑEZ, Salvador. "Del uso metalingüístico". En: Principios de sintaxis funcional. Madrid: Arco Libros, 1997, p. 381-393.

JOHNSON, Mark y George LAKOFF. Metáforas de la vida cotidiana. Madrid: Cátedra, 1986 [1980].

KABATEK, Johannes. Os falantes como lingüistas. Tradición, innovación e interferencias no galego actual. Vigo: Xerais, 2000.

LOUREDA LAMAS, Óscar. "Los juicios de valoración de los discursos en el español actual. Materiales para el estudio de la lingüística implícita en la lengua". Lingüística Española Actual, 1999, 21 (2), p. 207-220.

- "Sobre un tipo de marcadores discursivos de enumeración en el español actual". RILCE, 2000, 16 (2), p. 325-341.

— "Del metalenguaje y sus tipos (con especial referencia a los modos de significar)". Quaderni di Semantica, 2001, 21 (2), p. 287-333.

— "Polifonía y enumeración en el español actual". Oralia, 2002, 5, p. 133-151.

- Los nombres de los tipos de texto. El campo léxico 'lo que se dice' en el español actual. Pamplona: EUNSA, 2003.

— "Los hablantes como lingüistas. Algunas distinciones "pragmáticas" en el léxico del español". En: CASADO VELARDE, Manuel; Ramón GONZÁLEZ RUIZ y $\mathrm{M}^{\mathrm{a}}$ Victoria ROMERO GUALDA (eds.). Actas del Congreso Internacional "Análisis del discurso: lengua, cultura, valores". Madrid: Arco/Libros. En prensa a. 
LOUREDA LAMAS, Óscar. "La estructura del campo 'lo que se dice' en español actual". En: CASADO VELARDE, Manuel; Ramón GONZÁLEZ RUIZ y Óscar LOUREDA LAMAS (eds.). Estudios sobre lo metalingüístico en español. Frankfurt am Main: Peter Lang GmbH, Europaeischer Verlag der Wissenschaften. En prensa b.

MANERO RICHARD, Elvira. "La lingüística implícita en el refranero español de contenido metalingüístico". RILCE, 2000, 16 (2), p. 343-361.

- Aproximación a un estudio del refrán. El refranero español de contenido metalingüístico. Tesis de Licenciatura inédita. Pamplona: Universidad de Navarra, 2001.

RUIZ GURILLO, Leonor. Aspectos de fraseología teórica española. Valencia: Universidad, 1997.

- La fraseología en el español coloquial. Barcelona: Ariel, 1998.

WOTJAK, Gerd. "Uso y abuso de las unidades fraseológicas". En: ZAMORA VICENTE, Alonso (Hom.). Historia de la lengua. El español contemporáneo I. Madrid: Castalia, 1988, p. 535-548. 